identify over-commitment; strict application of rest and recovery policies; co-mentoring support within HR managers' networks in the hospice sector.

\section{P-271 SUSTAINING OUR WORKFORCE - PLACING STAFF SUPPORT AT THE HEART OF GOOD PRACTICE}

${ }^{1}$ Gill Thomas, ${ }^{2}$ Kath Blake, ${ }^{3}$ Tricia Wass. ${ }^{1}$ Princess Alice Hospice, Esher, UK; ${ }^{2}$ St Nicholas Hospice, Bury St Edmunds, UK; ${ }^{3}$ Tricia Wass Associates, Hove, UK

\subsection{6/bmjspcare-2018-hospiceabs.296}

Background With the UK demographic profile changing, people are living longer and more complex lives with progressive illness (Help the Hospices, 2012). This increases demand on palliative care professionals who have to respond to the needs of the population their serve. If recent mortality trends continue, Healthcare systems will need to adapt to the age-related growth in deaths of palliative care across health and social care disciplines (Etkind, Bone, Gomes et al., 2017). But how will hospices care for their staff knowing that burnout and compassion fatigue are the cost of caring in a healthcare setting (Brotheridge \& Grandey, 2002)?

Providing formal mechanisms for support will be essential to retain and sustain healthcare professionals and cultivate a climate of resilience. Clinical supervision is a working alliance between supervisor and supervisee with the aim of providing a safe and confidential environment for staff to reflect on and discuss their work and their personal and professional responses to their work. Seeking ways to embed an affordable, sustainable model of clinical supervision would benefit both hospices and their staff.

Aim 1) Explore different models of clinical supervision provided in hospices in the UK to understand current practice; 2) Develop a UK-wide debate about the application and impact of clinical supervision and its role in sustaining and retaining the palliative care workforce.

Method 1) UK-wide consultation with representation of hospices in different regions using video conferencing to understand the different models of clinical supervision; 2) Collate and disseminate findings; 3) Development of an adaptive model of supervision to use in any hospice setting.

Results We anticipate that this initiative will give an understanding of barriers and enablers to clinical supervision in hospices and develop a model of supervision that is easy to use, applicable in different settings, affordable and sustainable. In doing so, support palliative care professionals in a changing and increasingly challenging landscape.

\section{P-272 WHEN VOLUNTEERS MET AI: TRANSFORMING VOLUNTEER COMMUNICATIONS THROUGH CHATBOTS AND WORKPLACE}

Morven MacLean, Will McLean. Children's Hospices Across Scotland (CHAS), Edinburgh, UK

10.1136/bmjspcare-2018-hospiceabs.297

With a diverse volunteer base, it's difficult to find a method of communication to suit everyone. A recent review of volunteer communications allowed volunteers the opportunity to voice their views about the way in which CHAS communicates with them. Volunteers stated that communications were ad hoc, inconsistent and one-way. They wanted timely, relevant communications and a chance to share their views and network with others. They also favoured online communications.

A working group, chaired by a volunteer, was established in order to improve communications and identify an online communications platform, as requested by volunteers. The group researched options and decided that Workplace by Facebook was the most suitable platform. Free for charitable organisations, the platform has the same functionality/navigation as Facebook, making it very accessible.

A successful pilot led to the scaling up of the platform for all volunteers. With 500 sign-ups in less than the first six weeks, Workplace has transformed our volunteer communications and engagement, creating an opportunity for dialogue with volunteers, flattening hierarchy and enabling volunteers to access and receive real-time communications.

Workplace has strengthened the volunteer voice and improved the two-way communication with the organisation significantly. Volunteers have told us that they now feel more informed and connected to CHAS. Facebook analytics have allowed us to measure the success of the platform. We have harnessed digital technology (Workplace and the use of bots) to transform our volunteer communications and drive engagement. We are keen to showcase this project to other hospices as we feel it could enhance volunteer and employee communications in hospices across the country.

\section{P-273 'I ALWAYS DREAMED I WOULD BE A NURSE' - THE EMERGENCE OF ADULT CARE VOLUNTEERS}

Sue Marshall, Tricia Wilcocks. ellenor, Kent, UK

10.1136/bmjspcare-2018-hospiceabs.298

Background Staff working in a care setting should have a minimum training based on their Care Certificate (Cavendish, 2013). Sixth form students have been achieving a Care Certificate through a supported learning programme within the hospice (Wilcocks \& Marshall, 2017). Adult volunteers were inspired by what these students have achieved and asked if a similar opportunity could be provided to adults, enabling their volunteering time to support the clinical staff in a more practical way.

Aims Facilitating volunteers to develop care skills, in order to provide the hospice with a brand new team of 'Care Volunteers'.

Methods Volunteers who approached the education team were interviewed; four were accepted for a pilot project. A range of training and work plans were organised including:

- Induction in statutory and mandatory topics

- An overview of palliative care

- The outline of the Care Certificate standards and workbook

- Buddies allocated to monitor, support, advise, shadow and provide feedback

- Mobile messaging application used for communication and support

- Weekly tutorials and observations of competencies

- Practical competencies include moving and handling, personal care, nutrition and hydration.

Results Four adult volunteers completed their Care Certificate within eight weeks, working half a day a week. Two now work as care volunteers on inpatient ward, two have taken 
their care skills to the Hospice at Home team; one has been recruited to a paid role.

Quotes from Care Volunteers:

'I am so proud of myself ....taking on this learning at my age'

'I always dreamed I would be a nurse, now I feel my dream has pretty much come true'

Quote from Staff

'Invaluable'.... 'The support these learners are providing staff and families has already made a massive impact to our services'

Conclusion Comprehensive training can empower volunteers to provide a key role in supporting hands on patient care. Growing our own staff has now become a reality.

\section{P-274 EFFECTIVE VOLUNTEER SUPPORT ON AN INPATIENT UNIT (IPU)}

Rebekah Ashley, Ruth Blunt. Wigan and Leigh Hospice, Greater Manchester, UK

\subsection{6/bmjspcare-2018-hospiceabs.299}

Background We acknowledge the value of volunteers and identified a key part of volunteers feeling appreciated is ensuring they are integrated as part of the team. Review in the line management of volunteers for personable continuity. We explored the volunteer workforce, identifying development areas; shift patterns didn't fully support patients' needs, patients were not benefitting from volunteer interaction, there was crossover between nursing and volunteering duties. Inconsistencies within training and induction.

Aim To develop a beneficial volunteer support on the IPU, delivering specific training, enhancing skills and knowledge, enabling volunteers to safely fulfil their role whilst feeling empowered and valued as part of the wider team.

Method

- Review of duties led to a revised job description

- Established the qualities required to support poorly patients approaching end of life, which formed a person specification

- Recognition of volunteers' commitment and ours in a formal volunteer agreement

- Developing a code of conduct

- Designing specific training and a tailored induction covering relevant policies, procedures and guidelines

- Embedding the hospice values in every communication

- Streamlining duties and shift patterns to avoid duplication

- Updating volunteer contact/next of kin details and shift preferences.

We planned and developed a proposal, held consultation meetings discussing the proposed changes and how they incorporated into practice. This was then followed up with take home reference documents, and then awaited their feedback.

Results The process and improvements have transformed relationships, improved teamwork, empowered volunteers and tailored support for patients, carers and staff, creating cohesive specialist care.

Conclusion Volunteers have a good support network; receive a thorough induction, tailored training and biannual team meetings. Volunteers are more committed - reduced non-attendance. Shift patterns reduced - no duplication of duties. Database of contact details and availability.

\section{P-275 REDUCING BARRIERS TO VOLUNTEERING}

Vanessa Hill, Zoe Byrne. Princess Alice Hospice, Esher, UK

10.1136/bmjspcare-2018-hospiceabs.300

Background A report in 2012 recommended hospices explore new approaches to volunteering to develop skills and widen deployment of volunteers enabling hospices to extend their reach (Help the Hospices, 2012). We recognised the need to broaden the age range of our volunteers, with only $11 \%$ of our volunteers being under 35 years, and the need to develop and expand existing patient facing volunteer roles.

Aims To address barriers to volunteering; offer more flexible volunteer roles; review the areas where volunteers can provide additional support and widen participation.

Methods Survey sent to 950 volunteers; staff consultation and informal feedback from people applying to be volunteers.

Results We identified barriers to volunteering were type of role and rigid role specification. Many want a patient-facing role with flexibility in time commitment. The following initiatives were developed:

- a new, more hands-on ward based volunteer role

- increased range of tasks for teenage ward support volunteers

- volunteer roles attracting those unable to commit to regular days and times

- supporting patients with advance care planning

- discharge buddies supporting patients transitioning to home

- Partnership with a children's centre allowing young mums to commit to training and volunteering.

Our evaluation found for both patients and staff the experience has been positive with more diverse volunteer roles, flexibility in time and initiatives to support those with personal commitments with $7 \%$ more people volunteering in direct patient support. The average age of volunteers has reduced by three years since introducing a more varied volunteer programme.

Conclusions We have enhanced the level of support offered to patients through more hands-on volunteer roles and recognised the need for volunteers to use and develop their skills as well as the need for more flexible opportunities. The ability to provide childcare during volunteer training has enabled people who would traditionally not be available to become volunteers.

\section{P-276 TRANSFORMING VOLUNTEERING}

Minaxi Patel. LOROS Hospice, Leicester, UK

10.1136/bmjspcare-2018-hospiceabs.301

Background Volunteers contribute to patient care directly and indirectly, including the needs of carers, families and friends. There was a need to transform volunteering to make sure volunteering is safe, sustainable and transformational whilst supporting palliative care at the hospice. A new structure was developed to enable:

- Improved communication to and for volunteers

- A direct contact person for volunteers to go to with any concerns

- New processes and procedures to be put into place

- Promote volunteering opportunities for all departments

- Volunteers from all areas to be trained and supported 